\title{
Meta-analysis of ciprofloxacin in treatment of Crohn's disease
}

\author{
XIAO-WEI WU, HONG-ZAN JI and FANG-YU WANG \\ Department of Gastroenterology and Hepatology, Jinling Hospital, Medical School of Nanjing University, \\ Nanjing, Jiangsu 210002, P.R. China
}

Received September 13, 2014; Accepted September 18, 2014

DOI: $10.3892 /$ br. 2014.368

\begin{abstract}
The aim of the present study was to evaluate the efficacy of ciprofloxacin (cipro) for the treatment of Crohn's disease (CD) through a meta-analysis of randomized controlled trials. The PubMed, Embase and Cochrane Library databases were searched up to May 2014, with no language restrictions, for randomized placebo-controlled trials. Additional references were obtained from the reviewed studies. Five studies were in accordance with the criteria and were included in the meta-analysis. The pooled risk ratio (RR) of all the studies was 1.35 [95\% confidence interval $(\mathrm{CI}), 1.03-1.76$; $\mathrm{P}=0.03$ ]. In three studies, cipro was used for the treatment of $\mathrm{CD}$ with perianal fistula and the pooled RR was 1.66 (95\% CI, 1.16-2.39; $\mathrm{P}=0.006)$. In two studies, cipro was used to treat active $\mathrm{CD}$ and the pooled RR was 1.13 (95\% CI, 0.77-1.66; $\mathrm{P}=0.54)$. Thus in conclusion, cipro exhibits a significant efficacy for the treatment of $\mathrm{CD}$, in particular with perianal fistula.
\end{abstract}

\section{Introduction}

Crohn's disease (CD) is a chronic inflammatory disorder of the gastrointestinal tract and the pathogenesis is not entirely clear. Several factors are considered to contribute to the chronic intestinal inflammatory process in patients with CD. These factors include environmental exposures, a genetic disposition and an unbalanced immune reaction to the commensal microorganism of the gut $(1,2)$. The theoretical foundation for using antibiotics as the main CD treatment is based on increasing evidence implicating intestinal bacteria in the pathogenesis of the disease $(3,4)$. Certain clinical trials have demonstrated the efficacy of antibiotics in inducing and maintaining CD remission and preventing $C D$ recurrence (5). However, the use of antibacterial therapy for $\mathrm{CD}$ is also controversial, even this approach is frequently and successfully adopted in clinical practice (6).

Correspondence to: Dr Fang-Yu Wang, Department of Gastroenterology and Hepatology, Jinling Hospital, Medical School of Nanjing University, 305 East Zhongshan Road, Nanjing, Jiangsu 210002, P.R. China

E-mail: wangfangyu2014@126.com

Key words: Crohn's disease, ciprofloxacin, meta-analysis
The purpose of the present study was to evaluate the usefulness of ciprofloxacin (cipro), which is a staple antibiotic for treatment of CD. A meta-analysis was performed involving randomized controlled trials only.

\section{Materials and methods}

Inclusion/exclusion criteria. Studies that were in line with the following criteria were included: i) Randomized controlled trials that assess the efficacy of cipro for the treatment of CD; ii) studies that are published as a full article; and iii) other inflammatory bowel disease therapy allowed is the same in the two groups of the trial.

Studies were excluded if: i) Patients were $<18$ years, pregnant, had systemic disease, or had significant renal or hepatic disease; ii) specifically evaluate post-operative CD patients; and iii) the control group was not treated with placebo.

Search strategy. A search of the PubMed, Embase and Cochrane Library was performed up to May 2014. A search strategy was constructed using a combination of the following words: (Ciprofloxacin or quinolone or antibiotic) and (Crohn's disease or inflammatory bowel disease). Studies published in any language were included. A manual search of the references listed in the studies retrieved from the online databases and from previously published systematic reviews was also performed to identify further relevant studies.

Data extraction. Two investigators ( Wu and Ji) extracted data. Any difference regarding the study inclusion, data extraction and interpretation were resolved by consensus prior to the final analysis. Study variables were gathered in the following categories: Study design, demographics, interventions, duration, extent of disease and co-therapy permitted. To avoid the inclusion of duplicated data in final analysis, retrieved studies were carefully evaluated and checked by comparison of author names, geographical locations and period of study.

Assessment of risk of bias in included studies. The investigators independently, but without being blinded to the authors or journal, assessed the risk of bias in the studies that met the inclusion criteria. The Cochrane Collaboration's tool for assessing risk of bias in randomized trials (7) was used, which includes the following criteria: Adequacy random-sequence generation; allocation concealment; blinding of participants, personnel and outcome assessors; and incomplete outcome 
data. In all the cases, an answer of 'yes' indicates a low risk and an answer of 'no' indicates a high risk of bias.

Statistical methods. Meta-analysis was carried out by combining the risk ratio (RR) between the cipro and control groups of the individual studies in a global RR. The intention-to-treat analysis was performed that included all patients who started the medication. Statistical heterogeneity tested was performed using the $\chi^{2}$ statistic and $\mathrm{I}^{2}$, and an $\mathrm{I}^{2}$ value $>50 \%$ was considered to have substantial heterogeneity (8). A fixed-effects model was selected when the heterogeneity test showed $\mathrm{I}^{2}$ value $<50 \%$, otherwise, a random-effects model was used. Funnel plot was used as an indicator of publication bias (9). Analyses were conducted using Review Manager (RevMan software, version 5.3, 2014; The Nordic Cochrane Centre, The Cochrane Collaboration, Copenhagen, Denmark).

\section{Results}

Search results. The search identified 987 potentially relevant studies, of which 951 were excluded following title and abstract screening. In total, 36 studies were retained for full-text review. Initially, 18 review studies were discarded. By analyzing detail data, six retrospective studies and four uncontrolled studies were excluded. Two controlled studies were excluded as the control group was treated with non-placebo and another controlled study was excluded as it specifically evaluated post-operative patients. Finally, five studies (10-14) were identified involving 293 patients that fulfilled the inclusion criteria (Fig. 1).

Characteristics of included studies. The characteristics of included studies and patients are presented in Table I. Three studies came from North America, whereas the others were from Europe. There were $146(49.8 \%)$ males from the available data regarding the gender in all the studies. The mean age of patients ranged 30-45.2 years. In two studies, the intervention was monotherapy and there were 38 patients treated with cipro. In the other three studies, cipro groups were accepted with combination therapy. There were 45 patients treated with cipro plus anti-tumor necrosis factor and 66 patients treated with cipro plus metronidazole (metro) and budesonide. All the included trials had a number of methodological limitations (Table II).

Efficacy results. When including all the studies, there was a statistically significant effect of cipro used for induction of remission in $\mathrm{CD}$ patients at $10-12$ weeks $[\mathrm{RR}=1.35 ; 95 \%$ confidence interval (CI), 1.03-1.76; $\mathrm{P}=0.03$ ] (Fig. 2). Subgroup analysis was performed to assess the specific effects of cipro used for $C D$ with perianal fistula or active $C D$, respectively. Three studies $(11,13,14)$ involving 112 patients indicated that cipro had a specific affect in achieving remission of $C D$ with perianal fistula $(\mathrm{RR}=1.66$; 95\% $\mathrm{CI}, 1.16-2.39$; $\mathrm{P}=0.006)$. Two studies $(10,12)$ involving 181 patients did not appear to be specifically effective with regards to cipro inducing remission in active $\mathrm{CD}(\mathrm{RR}=1.13 ; 95 \% \mathrm{CI}, 0.77-1.66 ; \mathrm{P}=0.54)$.

Heterogeneity and publication bias. The present study did not cause significant heterogeneity in the meta-analysis $\left(\chi^{2}=6.37\right.$;

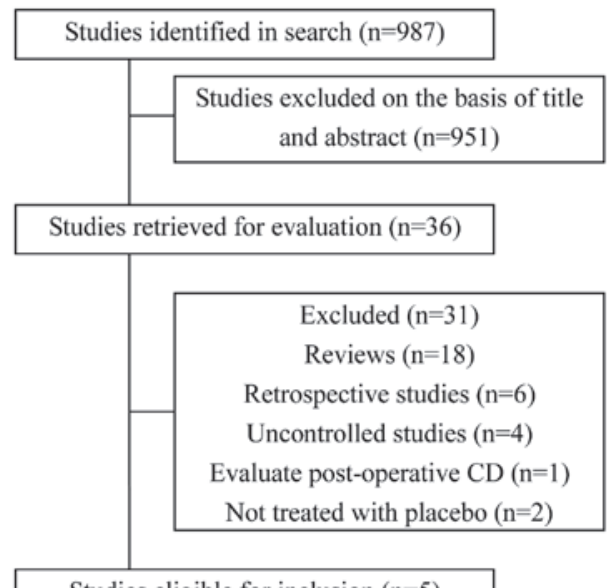

Studies eligible for inclusion $(n=5)$

Figure 1. Flow diagram of the study selection process. CD, Crohn's disease.

$\mathrm{I}^{2}=37 \%$; $\mathrm{P}=0.17$ ) (Fig. 2). Therefore, a fixed-effect model was used for the meta-analysis. A funnel plot is a helpful tool to estimate publication bias in a meta-analysis. Inspection of the funnel plot revealed a reasonably symmetrical distribution of studies. Accordingly, it was considered that there was no significant publication bias.

\section{Discussion}

With regards to the association between intestinal bacteria and $\mathrm{CD}$, numerous antibiotic regimens have been performed as primary therapy to try to modify the intestinal flora and reduce invasion and colonization of harmful bacteria (15). However, the role of intestinal bacteria in the pathogenesis of $\mathrm{CD}$ is not completely clear. Due to the complexity of intestinal microbial communities, all the harmful intestinal bacteria cannot be identified (16). Therefore, broad-spectrum antibiotics are considered more effective than narrow-spectrum antibiotics for the treatment of CD (17). Cipro is a quinolone with good activity against the majority of enteric bacteria (18) and the emergence of cipro resistance is relatively infrequent (19). Certain clinical trails have evaluated the efficacy of cipro for CD treatment.

In a small and uncontrolled study (20) of early stage, four active $C D$ patients were treated with cipro. Each patient had a significant improvement in abdominal pain and diarrhea coinciding with the institution of cipro. A retrospective study (21) involving 233 inpatients with active CD showed similar achievement rates of a complete or partial remission obtained between cipro plus metro or cipro alone. An uncontrolled trial (22) indicated that cipro in combination with metro was well-tolerated and beneficial for achieving clinical remission for patients with active $\mathrm{CD}$, particularly when there was involvement of the colon. A study (23) in Japan found that combination therapy of cipro and metro for four weeks significantly decreased the C-reactive protein in all the patients involved. In a randomized non-placebo controlled trial (24) involving $40 \mathrm{CD}$ patients, complete remission was observed in $56 \%$ patients treated with cipro and $55 \%$ patients treated with mesalazine. The result indicated that cipro was as effective as mesalazine in treating mild to moderate flare-up 
Table I. Characteristics of the studies included in the meta-analysis.

\begin{tabular}{|c|c|c|c|c|c|c|c|c|c|}
\hline \multirow[b]{2}{*}{ Study (year) } & \multirow[b]{2}{*}{ Country } & \multirow{2}{*}{$\begin{array}{c}\text { Study } \\
\text { population }\end{array}$} & \multirow{2}{*}{$\begin{array}{l}\text { Mean age, } \\
\text { years }\end{array}$} & \multirow{2}{*}{$\begin{array}{c}\text { Male, } \\
\%\end{array}$} & \multirow[b]{2}{*}{ Outcome } & \multicolumn{2}{|c|}{ Interventions } & \multirow{2}{*}{$\begin{array}{l}\text { Duration, } \\
\text { weeks }\end{array}$} & \multirow{2}{*}{ (Refs.) } \\
\hline & & & & & & Cipro & Control & & \\
\hline $\begin{array}{l}\text { Arnold et al } \\
(2002)\end{array}$ & USA & $\begin{array}{l}\text { Single- } \\
\text { center }\end{array}$ & 43 & 59.6 & CDAI $<150$ & Cipro $500 \mathrm{mg}$ bid & Placebo & 12 & (10) \\
\hline $\begin{array}{l}\text { Dewint et al } \\
(2014)\end{array}$ & $\begin{array}{l}\text { The } \\
\text { Netherlands }\end{array}$ & Multicenter & 36 & 52.9 & $\begin{array}{l}\geq 50 \% \text { reduction } \\
\text { of fistulas }\end{array}$ & $\begin{array}{l}\text { Cipro } 500 \mathrm{mg} \text { bid } \\
+ \text { adalimumab }\end{array}$ & $\begin{array}{l}\text { Placebo + } \\
\text { adalimumab }\end{array}$ & 12 & (11) \\
\hline $\begin{array}{l}\text { SteinWhart } \\
\text { et al (2002) }\end{array}$ & Canada & Multicenter & 32 & 42.5 & $\begin{array}{l}\text { CDAI }<150 \\
+ \text { budesonide }\end{array}$ & $\begin{array}{l}\text { Cipro } 500 \mathrm{mg} \text { bid } \\
\text { budesonide }\end{array}$ & Placebo + & 12 & (12) \\
\hline $\begin{array}{l}\text { Thia et al } \\
\text { (2009) }\end{array}$ & $\begin{array}{l}\text { USA/ } \\
\text { Canada }\end{array}$ & Multicenter & 35 & 67.7 & $\begin{array}{l}\geq 50 \% \text { reduction } \\
\text { of fistulas }\end{array}$ & Cipro 500 mg bid & Placebo & 10 & (13) \\
\hline $\begin{array}{l}\text { West et al } \\
(2004)\end{array}$ & $\begin{array}{l}\text { The } \\
\text { Netherlands }\end{array}$ & $\begin{array}{l}\text { Single- } \\
\text { center }\end{array}$ & 34 & 50.0 & $\begin{array}{l}\geq 50 \% \text { reduction } \\
\text { of fistulas }\end{array}$ & $\begin{array}{l}\text { Cipro } 500 \mathrm{mg} \text { bid } \\
+ \text { infliximab }\end{array}$ & $\begin{array}{l}\text { Placebo + } \\
\text { infliximab }\end{array}$ & 12 & (14) \\
\hline
\end{tabular}

Cipro, ciprofloxacin; CDAI, Crohn's disease activity index; bid, bis in die (twice daily).

Table II. Methodological quality summary for each included study.

\begin{tabular}{|c|c|c|c|c|c|}
\hline Study (year) & $\begin{array}{c}\text { Adequate } \\
\text { sequence generation }\end{array}$ & Allocation concealment & Blinding & $\begin{array}{c}\text { Incomplete } \\
\text { outcome data }\end{array}$ & (Refs.) \\
\hline Arnold et al (2002) & Yes & Unclear & No & Yes & $(10)$ \\
\hline Dewint et al (2014) & Yes & Unclear & Yes & Yes & (11) \\
\hline Steinhart et al (2002) & Yes & Unclear & Yes & Yes & (12) \\
\hline Thia et al (2009) & Yes & Unclear & Yes & Yes & (13) \\
\hline West et al (2004) & No & Unclear & Yes & Yes & (14) \\
\hline
\end{tabular}

Yes, low risk of bias; no, high risk of bias.

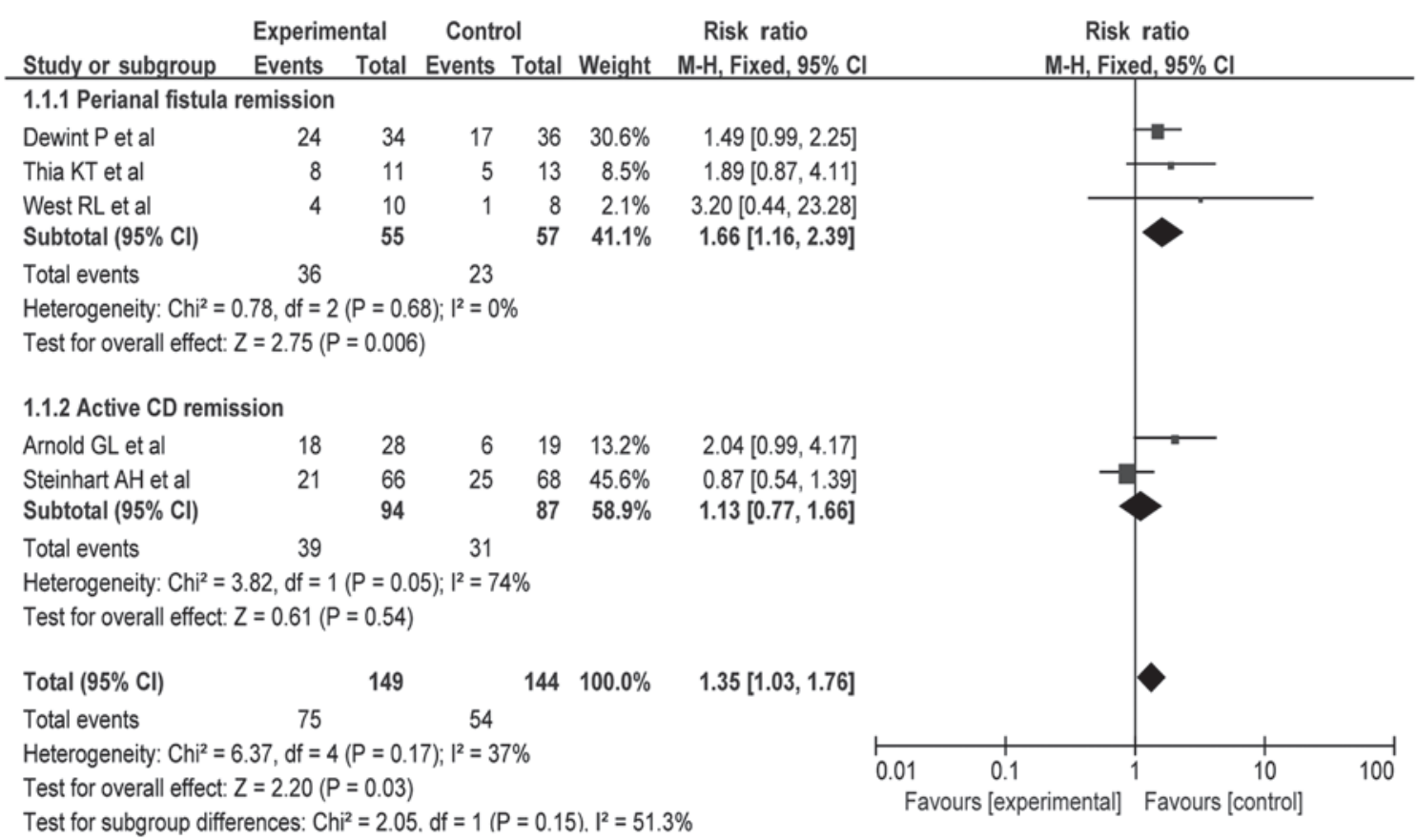


of CD. Another non-placebo controlled trial (25) involving 41 patients concluded that cipro plus metro could be an alternative to steroids in treating the acute phase of $\mathrm{CD}$.

Perianal fistula occurs in $\leq 40 \%$ of CD patients and its natural history is characterized by chronicity with rarely spontaneous healing of the fistula tracts (26). Despite enhancive medical and surgical treatment, the majority of patients continue to suffer from perianal symptoms and have to accept extensive surgery, such as proctocolectomy (27). Wolf (28) reported that five $\mathrm{CD}$ patients of perianal disease were treated with cipro for 1-2 months, which caused relief of symptoms and healing of fissures in four patients. Following discontinuation of cipro, three of the four responders underwent recurrence. Uza et al (29) carried out a combination therapy of cipro, metro and azathioprine to 10 patients with fistulizing CD. Complete responses were observed in all six patients with external fistulas, and in only one of four patients with internal fistulas. Turunen et al (30) treated 10 patients with severe perianal or fistulous $\mathrm{CD}$ with cipro for $\geq 3$ months and seven of the 10 patients responded. Two exhibited healed lesions $>2$ years and five others relapsed after discontinuing the antibiotic, but responded again to 1-3 month courses of cipro.

The present meta-analysis of five randomized placebo-controlled trials indicates that cipro is effective to relieve the activity of CD. In a study (12) involving 134 patients, cipro plus metro was ineffective to patients with active CD of the ileum, however this combination therapy may improve outcome when there is involvement of the colon. In another study (10), there was a significantly beneficial effect of cipro for treatment of active CD. After 3 months of therapy, remission was observed in $72 \%$ of patients treated with cipro and $50 \%$ of patients treated with placebo, respectively, and after 6 months of therapy the mean Crohn's disease activity index was 111.7 for the cipro group in contrast to 205.4 for the placebo group. However, the data of different remission rate according to the classification of disease location was absent. The other three studies included 112 patients with fistulizing CD. In two studies $(11,14)$ involving 45 patients treated with cipro plus anti-tumor necrosis factor, remission of fistulas was observed in $71 \%$ of patients treated with cipro and $45 \%$ of patients treated with placebo, respectively, and the results demonstrated that cipro was significantly effective to $\mathrm{CD}$ patients with perianal fistula. Another small sample size study (13) also showed fistula remission occurred more frequently in patients treated with cipro compared to treatment with placebo, but the differences were not significant.

However, the results of the present meta-analysis are limited. Firstly, the total number of samples in all the studies was not quite enough for a meta-analysis. Secondly, as the intervention in certain studies was combination therapy, it was difficult to accurately evaluate the effects of cipro. Furthermore, as the adverse events of cipro were not recorded clearly in each study, the side-effects of cipro used to treat CD could not be assessed. Therefore, the meta-analysis has specific bias and a globally multicenter prospective study is required to confirm the results.

In conclusion, the present meta-analysis showed that cipro is beneficial for CD patients, particularly with perianal fistula. However, the study is associated with certain limitations and it is necessary to conduct further prospective studies of cipro in CD patients.

\section{Acknowledgements}

The present study received financial support from the National Natural Science Foundation of China (grant no. 81270453).

\section{References}

1. Baumgart DC and Sandborn WJ: Crohn's disease. Lancet 380: 1590-1605, 2012

2. Cho JH and Brant SR: Recent insights into the genetics of inflammatory bowel disease. Gastroenterology 140: 1704-1712, 2011.

3. Perencevich M and Burakoff R: Use of antibiotics in the treatment of inflammatory bowel disease. Inflamm Bowel Dis 12: 651-664, 2006.

4. Sartor RB: Therapeutic manipulation of the enteric microflora in inflammatory bowel diseases: antibiotics, probiotics, and prebiotics. Gastroenterology 126: 1620-1633, 2004.

5. Prantera C: What role do antibiotics have in the treatment of IBD? Nat Clin Pract Gastroenterol Hepatol 5: 670-671, 2008.

6. Dignass A, Van Assche G, Lindsay JO, et al; European Crohn's and Colitis Organisation (ECCO): The second European evidence-based Consensus on the diagnosis and management of Crohn's disease: Current management. J Crohns Colitis 4: 28-62, 2010.

7. Higgins JP, Altman DG, Gotzsche PC, et al; Cochrane Bias Methods Group; Cochrane Statistical Methods Group: The Cochrane Collaboration's tool for assessing risk of bias in randomised trials. BMJ 343: d5928, 2011.

8. Higgins JP, Thompson SG, Deeks JJ and Altman DG: Measuring inconsistency in meta-analyses. BMJ 327: 557-560, 2003.

9. Egger M, Davey Smith G, Schneider M, et al: Bias in meta-analysis detected by a simple, graphical test. BMJ 315: 629-634, 1997.

10. Arnold GL, Beaves MR, Pryjdun VO and Mook WJ: Preliminary study of ciprofloxacin in active Crohn's disease. Inflamm Bowel Dis 8: 10-15, 2002

11. Dewint P, Hansen BE, Verhey E, et al: Adalimumab combined with ciprofloxacin is superior to adalimumab monotherapy in perianal fistula closure in Crohn's disease: a randomised, double-blind, placebo controlled trial (ADAFI). Gut 63: 292-299, 2014.

12. Steinhart AH, Feagan BG, Wong CJ, et al: Combined budesonide and antibiotic therapy for active Crohn's disease: a randomized controlled trial. Gastroenterology 123: 33-40, 2002.

13. Thia KT, Mahadevan U, Feagan BG, et al: Ciprofloxacin or metronidazole for the treatment of perianal fistulas in patients with Crohn's disease: a randomized, double-blind, placebo-controlled pilot study. Inflamm Bowel Dis 15: 17-24, 2009.

14. West RL, van der Woude CJ, Hansen BE, et al: Clinical and endosonographic effect of ciprofloxacin on the treatment of perianal fistulae in Crohn's disease with infliximab: a double-blind placebo-controlled study. Aliment Pharmacol Ther 20: 1329-1336, 2004.

15. Hammer HF: Gut microbiota and inflammatory bowel disease. Dig Dis 29: 550-553, 2011.

16. Chassaing B and Darfeuille-Michaud A: The commensal microbiota and enteropathogens in the pathogenesis of inflammatory bowel diseases. Gastroenterology 140: 1720-1728, 2011.

17. Prantera $C$ and Scribano ML: Antibiotics and probiotics in inflammatory bowel disease: why, when, and how. Curr Opin Gastroenterol 25: 329-333, 2009.

18. Hooper DC and Wolfson JS: Fluoroquinolone antimicrobial agents. N Engl J Med 324: 384-394, 1991.

19. Sanders CC, Sanders WE Jr and Goering RV: Overview of preclinical studies with ciprofloxacin. Am J Med 82: 2-11, 1987.

20. Peppercorn MA: Is there a role for antibiotics as primary therapy in Crohn's ileitis? J Clin Gastroenterol 17: 235-237, 1993.

21. Prantera C, Berto E, Scribano ML and Falasco G: Use of antibiotics in the treatment of active Crohn's disease: experience with metronidazole and ciprofloxacin. Ital J Gastroenterol Hepatol 30: 602-606, 1998.

22. Greenbloom SL, Steinhart AH and Greenberg GR: Combination ciprofloxacin and metronidazole for active Crohn's disease. Can J Gastroenterol 12: 53-56, 1998.

23. Ishikawa T, Okamura S, Oshimoto H, Kobayashi R and Mori M: Metronidazole plus ciprofloxacin therapy for active Crohn's disease. Intern Med 42: 318-321, 2003. 
24. Colombel JF, Lémann M, Cassagnou M, et al: A controlled trial comparing ciprofloxacin with mesalazine for the treatment of active Crohn's disease. Groupe d'Etudes Therapeutiques des Affections Inflammatoires Digestives (GETAID). Am J Gastroenterol 94: 674-678, 1999.

25. Prantera C,Zannoni F, Scribano ML, et al: An antibiotic regimen for the treatment of active Crohn's disease: a randomized, controlled clinical trial of metronidazole plus ciprofloxacin. Am J Gastroenterol 91: 328-332, 1996.

26. Lapidus A, Bernell O, Hellers G and Lofberg R: Clinical course of colorectal Crohn's disease: a 35-year follow-up study of 507 patients. Gastroenterology 114: 1151-1160, 1998.
27. Schwartz DA, Pemberton JH and Sandborn WJ: Diagnosis and treatment of perianal fistulas in Crohn disease. Ann Intern Med 135: 906-918, 2001.

28. Wolf J: Ciprofloxacin may be useful in Crohn's disease. Gastroenterology 98 (abstract): A212, 1990.

29. Uza N, Nakase H, Ueno S, et al: The effect of medical treatment on patients with fistulizing Crohn's disease: a retrospective study. Intern Med 47: 193-199, 2008.

30. Turunen U, Farkkila M, Valtonen V, et al: Longterm outcome of ciprofloxacin treatment in severe perianal or fistulous Crohn's disease. Gastroenterology 104 (abstract): A793, 1993. 